\title{
Combination of Transactional Analysis Therapy and Hypnotherapy in the Treatment of Emotional Conflicts: A Case Study in Iran
}

\author{
Zeynab Bahrami ${ }^{1} \&$ Atena Heidari ${ }^{2}$ \\ ${ }^{1}$ School of Psychology, University of New South Wales, Sydney, Australia \\ ${ }^{2}$ Faculty of Psychology and Educational Science, University of Tehran, Tehran, Iran \\ Correspondence: Atena Heidari, Faculty of Psychology and Educational Science, University of Tehran, Tehran, \\ Iran.
}

Received: January 15, 2021

Accepted: February 26, 2021

Online Published: March 1, 2021

doi:10.5539/ijps.v13n1p40

URL: https://doi.org/10.5539/ijps.v13n1p40

\begin{abstract}
The purpose of this study is to introduce a successful combination of transactional analysis therapy and hypnotherapy in the treatment of clients with emotional conflicts. The client was a 38-year-old woman who had visited a clinic due to family conflicts with her husband. Following the first stage of therapy, the family conflicts were resolved by problem focus therapy, so the client stopped the therapy. Yet she revisited the psychological clinic after three months. In the second six sessions, initially Transactional Analysis was used to solve the emotional conflicts. At the end of the sixth session, though, the therapist realized that some of the conflicts had remained unresolved. Therefore, the therapist decided to recreate the principles of transnational analysis indirectly through hypnotic trance and used this synthetic approach to act out emotionally and resolved the conflicts. In the follow-up sessions after the hypnotherapy, the client appeared stable and the therapist witnessed no disturbance in the client's behaviors and emotions. The client's emotional conflicts had been resolved.
\end{abstract}

Keywords: emotional conflict, hypnotherapy, transactional analysis

\section{Introduction}

Emotional conflict is the presence of different and opposing emotions related to a situation that has recently taken place or is in the process of being unfolded (Fenichel, 1946). It is a well-known fact that feelings and emotions play an important role in medical illnesses. Every kind of medical illness - mild, moderate or severe - is associated with emotions aroused to deal with it (Sifneos, 1991). Given the undeniable role of emotional conflicts in the development of mental disorders like anxiety (Amstadter, 2008) and depression (Fonzo et al., 2019), resolving these conflicts in treatment sessions is of great importance.

There are some studies investigating the effects of Transactional Analysis therapy (TA) on emotional conflicts. A study in Iran investigated the impacts of the Transactional Analysis program on emotion regulation among high school students and found that the Transactional Analysis program had a fairly logical effect on emotion regulation (Keshavarzi, Fathi Azar, Mirnasab, \& Badri Gargari, 2016). Transactional Analysis instruction allows individuals to modify the intensity and quality of emotions and moderate emotional disorders, such as anxiety and depression (Gross, 1998). In addition to TA, hypnotherapy has been suggested as another treatment for emotional conflicts (JM et al., 2015; Hunter, 2004; Lynn, \& Cardena, 2007). Hypnotic state allows people to explore painful thoughts, feelings, and memories they might have hidden from their conscious minds and resolve their emotional and cognitive conflicts (Bachner-Melman \& Lichtenberg, 2001). Empirical research has demonstrated that hypnotherapy can be integrated into overall Transactional Analysis treatment as an effective method to cathect the Child ego state for the purpose of behavioral changes (Selavan, 1975; Ford, 1989). This article aims to demonstrate the congruency between hypnotherapy and Transactional Analysis, and the benefits of developing TA techniques as a hypnotherapist.

In this paper, transactional analysis, hypnotherapy and the effectiveness of the combination of these two treatments according to the literature review were firstly introduced. The client and her problem were described in the second part. In the following section, the treatment plan and the content of the hypnotherapy session were explained. The final section included the results and conclusions of the study. 


\section{Transactional Analysis}

Eric Berne's analytical model is a humanistic method used in psychology (van Rijn, Wild \& Moran, 2011; Van Rijn \& Wil, 2013), communication (Hollins Martin, 2011), development (Callis, 1984; Nykodym, Nielsen, \& Christen, 2017), psychotherapy (Johnsson, 2011; Dixit \& Ramachandran, 2019) education (Joseph \& Chacko, 2012; Mei, 2010) and counseling (Vinella, 2013; Ostvar, Shiroodi, \& Karimi, 2018). The Transactional Analysis model assumes that people are seen to have a basic core which is lovable and all individuals have the potential and desire for growth and self-actualization (Yzeed, 2012). I'm OK, You're OK (Berne, 1962) implies that people have an innate worth and are selecting the best options they can (Hay, 2017).

The research used in this study is based on three ego states, the most basic concept of TA. Berne defined the ego state as coherent system of feeling and thinking patterns that are associated with a behavioral model (Keçeci \& Taşocak, 2009; Johnsson, 2011). Eric Berne was, originally, a Freudian psychologist and one area of similarity that can be seen between Berne and Freud is this tripartite system of personality. The three ego-states are known as Parent, Adult and Child, loosely analogous to Freud's id, ego, and super-ego (Booth, 2007; Mitra, 2020; Williams, 2012).

The Parent ego state is a set of thoughts, feelings, and behaviors that are learned or "borrowed" from our parents or other caretakers (Solomon, 2003; Berne, 1988; Williams, 2012). The Parent ego state can be divided into two functions: both Controlling (CP) and Nurturing (NP). The Controlling Parent is prejudged thoughts, feelings and beliefs that are learned from parents or parental figures and the part of the personality that criticizes, controls or finds fault. The Nurturing Parent is protecting and guarding (Keçeci \& Taşocak, 2009; Booth, 2007; Stewart \& Joines, 1987).

The Child ego state is the part of our personality that is the seat of emotions, thoughts, and feelings and all of the feeling state "memories" that we have of ourselves from childhood (Solomon, 2003; Berne, 1988). The Child is the natural uncontrolled and untutored energy of a child to explore, move, express itself, and instantly gratify its biological urges (Williams, 2012). The Child has both Free (FC) and Adapted (AC) function .The Free Child takes care of a person's physical needs, is spontaneous, does whatever he/she feels like doing, is active, creative, and is the uneducated side of a personality. The Adapted Child is the part of our personality that has learned to comply with the parental messages we received growing up (Keçeci \& Taşocak, 2009; Booth, 2007; Stewart \& Joines, 1987).

The Adult (A) ego state grows out of the child's increasing contact with the world as he or she develops reality-based skills and learns to manipulate things and events (Williams, 2012). The Adult ego-state is undivided and operates on the level of reason and rationality (Booth \& Parr, 2013).

\section{Hypnotherapy}

Generally, hypnotherapy creates a situation of focused arousal in which perceptual monitoring and consciousness are dissociated, so imagination and fantasies are commonly applied by the hypnotherapist (De Pascalis, 1998). Marmar (1959) and Davis (2016) defined it as psychophysiological tetrad of altered consciousness consisting of narrowed awareness, restricted and focused attentiveness, selective wakefulness, heightened suggestibility and reduced peripheral awareness characterized by an enhanced capacity for response to suggestion. Hypnosis has been used for millennia to induce trance to assist healing. Trance is a subjective state the highly hypnotizable person reports in response to a hypnotic induction (Wagstaff, 2010). The trance state may be induced using relaxation, deep breathing, meditation techniques, guided imagery, self-hypnosis, or hypnosis induction techniques (Shenefelt, 2002).

The three levels of the hypnotic state: Hypnoidal, Cataleptic and Somnambulistic State. Hypnoidal is a 'light' state of relaxation and inner focus and characterized by fluttering eye movements. Cataleptic State is a 'deepening' of the altered state and characterized by side to side eye movements. Somnambulistic State is the deepest 'trance state' characterized by rolling upwards of the eyes. Suggestions are received on an unconscious level and the person may have no memory of hearing about them (SIDIS, 1908).

Empirical research has demonstrated that hypnosis is a very effective intervention for a variety of problems and symptoms, including anxiety and depression (Valentine, Milling, Clark, \& Moriarty, 2019; Yapko, 2013; Holdevici \& Crăciun, 2013), psychosomatic disorder (Flammer \& Alladin, 2007; Satsangi \& Brugnoli, 2018; de Piano \& Salzberg, 1979), chronic pain (Elkins, Jensen, \& Patterson, 2007; Melis, Rooimans, Spierings, \& Hoogduin, 1991; Vlieger, Menko-Frankenhuis, Wolfkamp, Tromp, \& Benninga, 2007; Rutten et al., 2017) ,Problems Falling Asleep like insomnia (Graci \& Hardie, 2007; Anbar \& Slothower, 2006; Lam et al., 2015; Becker, 2015; Ng \& Lee, 2008), sexual disorders like vestibulitis syndrome (KANDYBA \& BINIK, 2003), 
arousal disorder (Elkins \& Ramsey, 2014), orgasmic disorder (Kraft \& Kraft, 2007) vaginismus (Mohammed, 2005; Pourhosein \& Bahrami, 2011), eating disorder like anorexia and obesity (Barabasz, 2007; Georgiou, 1995; Vanderlinden \& Vandereycken, 1994) Gastrointestinal Disorders (Miller, V., \& Whorwell, 2009; Vasant \& Whorwell, 2019; Palsson, 2015).

\section{Related Literature of Combination TA and Hypnotherapy}

The results across various conditions found that the addition of hypnosis substantially enhanced the therapy outcome. A recent meta-analysis of hypnosis for distress associated with medical procedures found that when the intervention was labeled as hypnosis instead of 'suggestion', they were significantly more effective (Hammond, 2010). Ford (1989) shows the potential potency available to the transactional analysis through the use of hypnosis, and thus the benefits of congruence between hypnotherapy and transactional analysis. According to this research hypnosis may be highly useful in providing access in therapy to the client's Child ego state. Hypnosis is a process whereby the person regresses to more archaic behaviors and states of feelings in the service of the ego. Thus, hypnosis is a state of altered ego functioning. Erickson (1967) sees the therapist in a supportive permissive role, using permission and protection to encourage and persuade the patient to take a stand and change. Therefore, in hypnosis, the patient functions from the Child ego state, while the therapist functions from the Parent ego state. As a result, through hypnosis the patient can be in touch with his Child ego state as T.A. sees it. He may then re-experience critical moments in his life that affected his present behavior. Re-experiencing these events gives the patient power over his situation and opens the possibility for him to make a re-decision in his Adult, and by this to change an unsatisfactory course of behavior (Selavan, 1975).

\section{Aims and Hypothesis}

The purpose of this case study is to introduce effective evidence for using combination of hypnotherapy with TA techniques in the treatment of client with emotional conflicts. Although the current study is only a case study, it can certainly open up new horizons for researchers to conducting more experimental and correlational studies to find stronger evidence of the effectiveness of these treatments. In fact, the TA therapist can utilize hypnosis as a direct and effective short cut to cathect the Child ego state of the client as in overcoming Parental influences that may give negative messages that are obstacles to change. Accordingly, this article focuses on the question of whether combining hypnotherapy with TA can treat clients with emotional conflicts. The subject of the study provided written consent for the report. Her full name and job will remain confidential.

\section{Diagnostic Assessment}

The client was a 38-year-old woman who had visited a private psychological clinic in Tehran due to family conflicts with her husband. Following the first stage of therapy which included six sessions, the family conflicts were resolved by problem focus therapy, so the client stopped the therapy. Yet she revisited the mental health clinic after three months. In the second stage of therapy, the client digressed from talking about her problems in the first few sessions but eventually confessed to conflicts with her mother in the third session. Therefore, the therapist started a Transactional Analysis in the upcoming sessions, focusing on the conflicts with the mother. Although the client avoided addressing her conflicts with her mother, the therapist provided the client with a chance to acknowledge this issue whenever she felt comfortable to do so. Eventually, the client went through an extreme emotional act out concerning her mother in the sixth session.

The client reported that she had been the last child in the family and there had been a big age gap between her and her siblings. As a child, she always felt to be neglected by her mother. Her older siblings got married when she was a child, so her needs were overlooked. According to the client, her mother had taken a strict cognitive-behavioral training approach, refraining from physical touch with her child, leaving the child always looking for her mother. The client stated that at the age of 11, she made friends with a boy on her way back home from school. Although their friendship was only limited to the journey from home to school and vice versa, her mother punished her when she found out about her new friend, and the idea of "You're not a good girl" leaded to a feeling of anger and resentment towards her mother. This extreme feeling of anger was addressed as the core of the conflict in the therapy session. The client admitted that she couldn't forgive her mother at the very same session and the pattern of behavioral conflict with the mother was identified as withdrawal-avoidance.

\section{Treatment Plan and Interventions}

In the second six sessions, initially Transactional Analysis was used to solve the cognitive conflicts. At the end of the sixth session, though, the therapist realized that some of the conflicts had remained unresolved and the patient did not consciously show any anger and resentment towards her mother. Therefore, the therapist decided to recreate the principles of Transnational Analysis indirectly through hypnotic trance and used this synthetic 
approach to act out emotionally and resolved the conflicts. The patient quickly went into a hypnotic trance state in the hypnotherapy session. During hypnosis, the patient's tic in her hands was evident, so apparently, the patient had gotten involved in the hypnotic trance. Subsequently, the patient explained her understanding of the hypnotic trance after the hypnosis. In the next session, the client explained that she had visited her mother and had asked her mother to hug her. Her mother had accepted to hug her, so the patient had realized that the hug had satisfied the mother's need, too. As a result, the conflict was resolved, and the client managed to forgive and understand her mother.

\section{The Content of the Hypnotherapy Session in Resolving Emotional Conflicts}

The process began with relaxation techniques, and the client finally went into a hypnotic trance. The client explained the trance as a field filled with flowers, butterflies, and a tree in the middle of the field. The patient mentioned an old willow tree, while the therapist had only suggested a tree. The client said that the little girl who had been crying behind the tree was herself. The client had asked the little girl why she had been crying and the little girl had said that she had hurt her hand with a branch of the tree and that the tree had hurt her. The client had asked the tree why it had hurt the girl, and the tree had said the little girl had scratched its trunk. The patient had been asked to reconcile the little girl and the tree. The patient hugged the little girl, bandaged the little girl's hand, restored the tree trunk, and then embraced the little girl and the tree at the same time. This stage of the trance continued in silence for about 1 to 2 minutes. Then, the hypnosis ended. When the patient left the trance, she said that she knew the tree behind which the little girl had been crying was her mother.

The patient felt calm and stable in the follow-up session. There have been proper interactions between the client and her mother and the client had easily hugged her mother. The client's emotional conflicts had been resolved. She claimed that her relationship with her husband and child had improved and that she had focused on her goals. In the four upcoming sessions, the client appeared stable and the therapist witnessed no disturbance in the client's behaviors and emotions.

\section{Results and Conclusions}

The clinical observations of the psychologist and the client's reports of her behaviors, emotions, and thoughts proved the effectiveness of the therapy. This case study shows how transactional analysis could be combined with hypnotherapy. Inducing the concepts of transactional analysis in a hypnotic trance about emotional conflicts made deep, stable changes in the client. It is worth adding that two psychological interventions were included in treating the client:

The first intervention included utilizing transactional analysis concepts to resolve the client's cognitive conflicts. In fact, at this stage, the therapist tried to familiarize the client with different mental states and illustrated a psychological structure of the client's character from a transactional analysis point of view. The final aim of the transactional analysis is to help patients resolve their cognitive and emotional conflicts with healthier mental states and more proper relationships (Bern, 1988). In this case study, the client had formed an unsafe attachment due to her lack of emotional and physical access to her mother, believing that she was not a decent, lovable person and did not deserve her mother's unconditional care and love (Solomon, 2003). These results are not based on reality, yet they are assumptions made based on the individual's initial decisions (Johnson, 2011). In fact, the client becomes aware of the fact that she has been constraining herself thanks to her obsolete childhood strategies. Moreover, her unfulfilled childhood needs had created a deep feeling of anger and resentment toward her mother. Besides, the main problem with this client was that her child mental state could need to face this conflict and did not know how to resolve it. A permanent feeling of aggression had been created in the client's mind because of the "You're not a good girl" message.

In the second stage of the therapy, the therapist tried to approach the client's emotional conflicts using a hypnotic trance. She tried to help the client's inner child to face this conflict and resolve it. Therefore, the success of this case study is due to implementing a combination of transactional analysis and hypnotherapy. Following the hypnotic trance, the client admits that the tree behind which the little girl was hiding was her mother. Needless to say that the therapist had never mentioned this to the client. Identifying mental states helped the client to face her child mental states during the hypnotic trance. She expressed how angry she was with her mother, and that is how she manages to forgive her mother after all those years.

The limitation of this study is the lack of experimental evidence which leads to not being able to discuss the cause and effect relationships of transactional analysis and hypnotherapy in resolving the emotional conflicts of the client. However, this case study can pave the way for future research that can reduce the limitations of the current study. Moreover, we suggest to researchers to examine the impacts of these two kinds of therapies in an experimental design on three groups of participants. The first could receive transactional analysis, the second 
might be given hypnotherapy, and the third can be provided with a combination of both.

\section{References}

Amstadter, A. (2008). Emotion regulation and anxiety disorders. Journal of anxiety disorders, 22(2), 211-221. https://doi.org/10.1016/j.janxdis.2007.02.004

Anbar, R. D., \& Slothower, M. P. (2006). Hypnosis for treatment of insomnia in school-age children: a retrospective chart review. BMC pediatrics, 6(1), 23. https://doi.org/10.1186/1471-2431-6-23

Bachner-Melman, R., \& Lichtenberg, P. (2001). Freud's relevance to hypnosis: A reevaluation. American Journal of Clinical Hypnosis, 44(1), 37-50. https://doi.org/10.1080/00029157.2001.10403454

Barabasz, M. (2007). Efficacy of hypnotherapy in the treatment of eating disorders. Intl. Journal of Clinical and Experimental Hypnosis, 55(3), 318-335. https://doi.org/10.1080/00207140701338688

Becker, P. M. (2015). Hypnosis in the management of sleep disorders. Sleep medicine clinics, 10(1), 85-92. https://doi.org/10.1016/j.jsmc.2014.11.003

Berne, E. (1988). What Do You Say After You Say Hello. Bantam Books, 10th Printing, New York.

Booth, L. (2007). Observations and reflections of communication in health care-could Transactional Analysis be used as an effective approach? Radiography, 13(2), 135-141. https://doi.org/10.1016/j.radi.2006.01.010

Booth, L., \& Parr, J. (2013). Student radiographers' personality; constant or individual differences in change? A transactional analysis approach. European Scientific Journal, 9(24), 130-142.

Boris Sidis. (1909). An Experimental Study of Sleep: (from the Physiological Laboratory of the Harvard Medical School and from Sidis Laboratory). Badger.

Callis, S. (1984). Transactional Analysis in management development. Education+ Training, 26(7), 198-199. https://doi.org/10.1108/eb017040

Davis, E. (2016). Literature review of the evidence-base for the effectiveness of hypnotherapy. Melbourne: PACFA.

De Pascalis, V. (1998). Hypnosis, Attention and Consciousness: Psychological. International Journal of Psychophysiology, 30, 7-94. https://doi.org/10.1016/S0167-8760(98)90059-9

De Piano, F. A., \& Salzberg, H. C. (1979). Clinical applications of hypnosis to three psychosomatic disorders. Psychological Bulletin, 86(6), 1223. https://doi.org/10.1037/0033-2909.86.6.1223

Dixit, V., \& Ramachandran, K. (2019). Transactional analysis: A marital therapy. Indian Journal of Health and Wellbeing, 10(10), 362-367.

Elkins, G. R., Ramsey, D., \& Yu, Y. (2014). Hypnotherapy for persistent genital arousal disorder: a case study. International Journal of Clinical and Experimental Hypnosis, 62(2), 215-223. https://doi.org/10.1080/00207144.2014.869136

Elkins, G., Jensen, M. P., \& Patterson, D. R. (2007). Hypnotherapy for the management of chronic pain. Intl. Journal of Clinical and Experimental Hypnosis, 55(3), 275-287. https://doi.org/10.1080/00207140701338621

Fenichel, O. (1946). The Psychoanalytic Theory of Neurosis London. Kegan Paul, Trench, Trubner \& Co., Ltd.

Flammer, E., \& Alladin, A. (2007). The efficacy of hypnotherapy in the treatment of psychosomatic disorders: Meta-analytical evidence. Intl. Journal of Clinical and Experimental Hypnosis, 55(3), 251-274. https://doi.org/10.1080/00207140701338696

Fonzo, G. A., Etkin, A., Zhang, Y., Wu, W., Cooper, C., Chin-Fatt, C., ... Trivedi, M. H. (2019). Brain regulation of emotional conflict predicts antidepressant treatment response for depression. Nature human behaviour, 3(12), 1319-1331. https://doi.org/10.1038/s41562-019-0732-1

Ford, L. B. (1989). Ericksonian hypnotherapy and transactional analysis: an effective blend. Transactional Analysis Journal, 19(4), 235-239. https://doi.org/10.1177/036215378901900408

Georgiou, E. (1995). Hypnotherapy in the treatment of anorexia tardive. Australian Journal of Clinical \& Experimental Hypnosis, 23(1), 14-24.

Graci, G. M., \& Hardie, J. C. (2007). Evidenced-based hypnotherapy for the management of sleep disorders. Intl. Journal of Clinical and Experimental Hypnosis, 55(3), 288-302. https://doi.org/10.1080/00207140701338662 
Gross, J. J. (1998). The emerging field of emotion regulation: An integrative review. Review of general psychology, 2(3), 271-299. https://doi.org/10.1037/1089-2680.2.3.271

Hammond, D. C. (2010). Hypnosis in the treatment of anxiety-and stress-related disorders. Expert review of neurotherapeutics, 10(2), 263-273. https://doi.org/10.1586/ern.09.140

Hay, J. (2017). An Introduction to Transactional Analysis Psychotherapy. Journal of Experiential Psychotherapy/Revista de PSIHOterapie Experientiala, 20(3).

Holdevici, I., \& Crăciun, B. (2013). Hypnosis in the treatment of patients with anxiety disorders. Procedia-Social and Behavioral 471-475. https://doi.org/10.1016/j.sbspro.2013.04.333

Hollins Martin, C. J. (2011). Transactional analysis: A method of analysing communication. British Journal of Midwifery, 19(9), 587-593. https://doi.org/10.12968/bjom.2011.19.9.587

Hunter, R. (2004). Hypnosis for inner conflict resolution: Introducing parts therapy. Crown House Publishing.

J. M., Badosa, Camino, A., Feixas, G., Gironell, A., Juan, E., \& Maggio, D. (2015). Conversion Disorder (CD) Hypnosis Treatment, according to Camillo Loriedo's naturalistic approach Case Study. Conference: Primeras Jornadas de la Sociedad Española de Medicina Psicosomática At: Madrid.

Johnsson, R. (2011). Transactional Analysis Psychotherapy-Three Methods Describing a Transactional Analysis Group Therapy. Lund University. https://doi.org/10.29044/v2i2p3

Joseph, M. R., \& Chacko, T. V. (2012). Transactional analysis (TA): a learning-teaching tool for faculty development. South-East Asian Journal of Medical Education, 6(1). https://doi.org/10.4038/seajme.v6i1.186

KaNDYBA, K., \& BINIK, Y. M. (2003). Hypnotherapy as a treatment for vulvar vestibulitis syndrome: a case report. Journal of Sex \& Marital Therapy, 29(3), 237-242. https://doi.org/10.1080/00926230390155122

Keçeci, A., \& Taşocak, G. (2009). Nurse faculty members' ego states: Transactional Analysis Approach. Nurse Education Today, 29(7), 746-752. https://doi.org/10.1016/j.nedt.2009.02.013

Keshavarzi, S., Fathi Azar, E., Mirnasab, M. M., \& Badri Gargari, R. (2016). Effects of a Transactional Analysis Program on Adolescents' Emotion Regulation. International Journal Psychological Studies, 8(4), 51-60. https://doi.org/10.5539/ijps.v8n4p51

Kraft, T., \& Kraft, D. (2007). The place of hypnosis in psychiatry, Part 2: Its application to the treatment of sexual disorders. Australian Journal of Clinical and Experimental Hypnosis, 35(1), 1-18.

Lam, T. H., Chung, K. F., Yeung, W. F., Yu, B. Y. M., Yung, K. P., \& Ng, T. H. Y. (2015). Hypnotherapy for insomnia: a systematic review and meta-analysis of randomized controlled trials. Complementary therapies in medicine, 23(5), 719-732. https://doi.org/10.1016/j.ctim.2015.07.011

Lynn, S. J., \& Cardena, E. (2007). Hypnosis and the treatment of posttraumatic conditions: An evidence-based approach. Intl. Journal of Clinical and Experimental Hypnosis, 55(2), 167-188. https://doi.org/10.1080/00207140601177905

Marmer, M. J. (1959). Hypnosis in Anesthesiology. Springfield III: Charles C Thomas Publisher.

Mei, Y. (2010). The Relationship between teaching transactional analysis theory and college students' locus of control: An empirical research. International Journal of Transactional Analysis Research \& Practice, 1(1). https://doi.org/10.29044/v1i1p40

Melis, P. M., Rooimans, W., Spierings, E. L., \& Hoogduin, C. A. (1991). Treatment of chronic tension-type headache with hypnotherapy: A single-blind time controlled study. Headache: The Journal of Head and Face Pain, 31(10), 686-689. https://doi.org/10.1111/j.1526-4610.1991.hed3110686.x

Miller, V., \& Whorwell, P. J. (2009). Hypnotherapy for functional gastrointestinal disorders: a review. Intl. Journal of Clinical and Experimental Hypnosis, 57(3), 279-292. https://doi.org/10.1080/00207140902881098

Mitra, I. (2020). Transactional Analysis and Spirituality. International Journal of Transactional Analysis Research \& Practice, 11(1), 80-94. https://doi.org/10.29044/v11i1p80

Mohammed, A. (2005). Al Sughayir, Vaginismus treatment Hypnotherapy versus behavior therapy. Neurosciences, 10(2), 163-167. 
Ng, B. Y., \& Lee, T. S. (2008). Hypnotherapy for sleep disorders. Annals Academy of Medicine Singapore, 37(8), $683-688$

Nykodym, N., Nielsen, W. R., \& Christen, J. C. (1985). Can organization development use transactional analysis? Transactional Analysis Journal, 15(4), 278-284. https://doi.org/10.1177/036215378501500407

Ostovar, J., Ghorban Shiroodi, S., \& Karimi, B. (2018). The effect of participation in group counseling sessions of transactional analysis on the marital burnout, adjustment and intimacy. Family Pathology, Counseling and Enrichment Journal, 3(2), 21-44.

Palsson, O. S. (2015). Hypnosis treatment of gastrointestinal disorders: a comprehensive review of the empirical evidence. American Journal of Clinical Hypnosis, 58(2), 134-158. https://doi.org/10.1080/00029157.2015.1039114

Pourhosein, R., \& Ehsan, Z. B. (2011). Using hypnosis in a case of vaginismus: a case report. Procedia-Social and Behavioral Sciences, 15, 3886-3889. https://doi.org/10.1016/j.sbspro.2011.04.389

Rijn, B. V., \& Wild, C. (2013). Humanistic and integrative therapies for anxiety and depression: Practice-based evaluation of transactional analysis, gestalt, and integrative psychotherapies and person-centered counseling. Transactional Analysis Journal, 43(2), 150-163. https://doi.org/10.1177/0362153713499545

Rutten, J. M., Vlieger, A. M., Frankenhuis, C., George, E. K., Groeneweg, M., Norbruis, O. F., \& Benninga, M. A. (2017). Home-based hypnotherapy self-exercises vs individual hypnotherapy with a therapist for treatment of pediatric irritable bowel syndrome, functional abdominal pain, or functional abdominal pain syndrome: a randomized clinical trial. Jama Pediatrics, 171(5), 470-477. https://doi.org/10.1001/jamapediatrics.2017.0091

Satsangi, A. K., \& Brugnoli, M. P. (2018). Anxiety and psychosomatic symptoms in palliative care: from neuro-psychobiological response to stress, to symptoms' management with clinical hypnosis and meditative states. Annals of Palliative Medicine, 7(1), 75-111. https://doi.org/10.21037/apm.2017.07.01

Selavan, A. (1975). Hypnosis and transactional analysis theory. American Journal of Clinical Hypnosis, 17(4), 260-262. https://doi.org/10.1080/00029157.1975.10403753

Shenefelt, P. D. (2002). Complementary psychotherapy in dermatology: hypnosis and biofeedback. Clinics in dermatology, 20(5), 595-601. https://doi.org/10.1016/S0738-081X(02)00264-X

Sifneos, P. E. (1991). Affect, emotional conflict, and deficit: an overview. Psychotherapy and psychosomatics, 56(3), 116-122. https://doi.org/10.1159/000288543

Solomon, C. (2003). Transactional analysis theory: The basics. Transactional analysis journal, 33(1), 15-22. https://doi.org/10.1177/036215370303300103

Stewart, I., \& Joines, V. (1987). TA Today: A new introduction to Transactional analysis. Lifespace publishing: Oxford, England.

Valentine, K. E., Milling, L. S., Clark, L. J., \& Moriarty, C. L. (2019). The efficacy of hypnosis as a treatment for anxiety: a meta-analysis. International Journal of Clinical and Experimental Hypnosis, 67(3), 336-363. https://doi.org/10.1080/00207144.2019.1613863

Van Rijn, B., Wild, C., \& Moran, P. (2011). Evaluating the outcomes of transactional analysis and integrative counselling psychology within UK primary care settings. International Journal of Transactional Analysis Research \& Practice, 2(2). https://doi.org/10.29044/v2i2p34

Vanderlinden, J., \& Vandereycken, W. (1994). The (limited) possibilities of hypnotherapy in the treatment of $\begin{array}{llll}\text { obesity. American journal of clinical hypnosis, 36(4), } & \text { 248-257. }\end{array}$ https://doi.org/10.1080/00029157.1994.10403084

Vasant, D. H., \& Whorwell, P. J. (2019). Gut-focused hypnotherapy for Functional Gastrointestinal Disorders: Evidence-base, practical aspects, and the Manchester Protocol. Neurogastroenterology \& Motility, 31(8), e13573. https://doi.org/10.1111/nmo.13573

Vinella, P. (2013). Transactional analysis counseling groups: Theory, practice, and how they differ from other TA groups. Transactional Analysis Journal, 43(1), 68-79. https://doi.org/10.1177/0362153713486111

Vlieger, A. M., Menko-Frankenhuis, C., Wolfkamp, S. C., Tromp, E., \& Benninga, M. A. (2007). Hypnotherapy for children with functional abdominal pain or irritable bowel syndrome: a randomized controlled trial. Gastroenterology, 133(5), 1430-1436. https://doi.org/10.1053/j.gastro.2007.08.072 
Wagstaff, G. F. (2010). Hypnosis and the relationship between trance, suggestion, expectancy and depth: Some semantic and conceptual issues. American Journal of Clinical Hypnosis, 53(1), 47-59. https://doi.org/10.1080/00029157.2010.10401746

Widdowson, M. (2014). Transactional analysis psychotherapy for a case of mixed anxiety \& depression: A pragmatic adjudicated case study-'Alastair'. International Journal of Transactional Analysis Research \& Practice, 5(2). https://doi.org/10.29044/v5i2p66

Yapko, M. D. (Ed.). (2013). Hypnosis and treating depression: Applications in clinical practice. Routledge. https://doi.org/10.4324/9780203957073

Yzeed, M. H.-E. (2012). Transactional Analysis Model Used by Faculty Members in Their Interaction with Nursing Students. Journal of American Science, 8(10), 603-611. https://doi.org/10.21511/ppm.18(1).2020.13

\section{Copyrights}

Copyright for this article is retained by the author(s), with first publication rights granted to the journal.

This is an open-access article distributed under the terms and conditions of the Creative Commons Attribution license (http://creativecommons.org/licenses/by/4.0/). 